\title{
Is there a Role of Routine Use of Topical Tranexamic Acid in Hemiarthroplasty?
}

\author{
Aditya Aggarwal ${ }^{1}$, Pankaj Mahindra², Rajnish Garg ${ }^{3}$, Harpal S Selhi ${ }^{4}$
}

\begin{abstract}
Background: Blood loss is one of the major perioperative problems in elderly patients undergoing hemiarthroplasty. Such patients, if they require blood transfusion, may be exposed to the complications associated with the same. Intravenous tranexamic acid (TXA) has been used with success in preventing blood loss in total knee arthroplasty and total hip arthroplasty. Concern about thromboembolic complications has led to the topical use of TXA in both TKA and THA. We prospectively evaluated the efficacy of topical TXA for reduction of blood loss in patients undergoing hemiarthroplasty and the related need for blood transfusion.

Materials and methods: Fifty-nine patients aged more than 60 years who presented with a fresh femoral neck fracture and were planned for hemiarthroplasty were randomly divided into two groups. Twenty-nine patients (study group) had local use of TXA during surgery, and 30 patients (control) had only placebo. Postoperative blood loss estimation was compared, which was estimated by hemoglobin (Hb) balance formula based on the postoperative fall of hemoglobin and hematocrit when compared to preoperative values. Complications such as postoperative bleeding, rehabilitation delays, and infection rates were documented.

Results: The $\mathrm{Hb}$ decline on the fifth postoperative day in the study group was $1.15 \pm 0.40 \mathrm{~g} / \mathrm{dL}$ in contrast to $1.97 \pm 0.60 \mathrm{~g} / \mathrm{dL}$ in the control group ( $p$ value 0.001 ). The blood loss in the study group was $694.14 \mathrm{~mL}$ when compared to $1000.2 \mathrm{~mL}$ in the control group patients ( $p$ value 0.001 ).

Conclusion: Despite inherent limitations, the study demonstrated effectiveness of topical use of TXA for decreasing blood loss and reducing need of blood transfusion in hemiarthroplasty patients.

Keywords: Blood loss, Fracture neck of femur, Hemiarthroplasty, Hip fracture, Topical, Tranexamic acid.

Journal of Postgraduate Medicine, Education and Research (2020): 10.5005/jp-journals-10028-1397
\end{abstract}

\section{INTRODUCTION}

Hip fractures are a serious threat to the quality of life and survival. These fractures with or without treatment are associated with high morbidity and mortality within the first year after injury. The incidence of hip fractures in the age-group more than 35 years is estimated to increase from 1.66 million in 1990 to 6.26 million by 2050. ${ }^{1}$ According to a 2017 report from the National hip fracture database, the incidence of hip fractures in the United Kingdom is 77,000 per year, and hemiarthroplasty is the commonest surgical procedure for treatment of fracture neck femur in elderly patients. ${ }^{2}$ Surgery in these frail patients is limited by the possibility of blood loss during surgery and the overall poor physical condition of the patient.

Inspired by the success of intravenous tranexamic acid (TXA) in preventing blood loss, various surgeons have resorted its topical use in total knee arthroplasty (TKA). It has been topically used in a dosage of $1-4 \mathrm{~g}$ without any complications. ${ }^{3-5}$ In TKA, tourniquet is also being used, and there is increase in fibrinolysis on release of the tourniquet, thus the requirement for antifibrinolytics. ${ }^{6}$ In hip surgery, a tourniquet cannot be used, and the utility of antifibrinolytics may be different. Many surgeons have studied the role of intravenous TXA in total hip arthroplasty (THA) and found it useful. With the aim of minimizing any possible complications such as thromboembolic phenomena, there is an increasing interest in topical use. Topical use has been found effective in THA, but it remains to be seen whether it can be recommended for routine use in hemiarthroplasty $(H A)$. The present study was designed to study the role of topical TXA in patients undergoing $\mathrm{HA}$. \begin{tabular}{l}
\hline \hline${ }^{1}$ Department of Orthopaedics, Postgraduate Institute of Medical \\
Education and Research, Chandigarh, India \\
${ }^{2-4}$ Department of Orthopaedics, Dayanand Medical College and \\
Hospital, Ludhiana, Punjab, India \\
Corresponding Author: Aditya Aggarwal, Department of \\
Orthopaedics, Postgraduate Institute of Medical Education and \\
Research, Chandigarh, India, Phone: +91 8284994910, e-mail: \\
dr.aditya.agg@gmail.com \\
How to cite this article: Aggarwal A, Mahindra P, Garg R, et al. Is there \\
a Role of Routine Use of Topical Tranexamic Acid in Hemiarthroplasty? \\
J Postgrad Med Edu Res 2020;54(4):244-247. \\
Source of support: Nil \\
Conflict of interest: None \\
\hline \hline
\end{tabular}

\section{Materials and Methods}

The study was a placebo-controlled prospective study on patients undergoing cemented HA of hip joint at a tertiarycare institution after obtaining approval from the institutional ethics committee. Patients with preexisting coagulopathies or those who presented with concomitant inflammatory, pyogenic, or tubercular arthritis of the hip joint and patients with any disease condition that precluded the use of TXA were excluded from the study. Out of a total of 69 patients, 10 were excluded because of the same.

The patients were divided in two groups. The study group (29 patients) were given a total of $3 \mathrm{~g}$ of topical TXA diluted with normal saline in two divided doses, $1.5 \mathrm{~g}$ made to a total volume of $50 \mathrm{~mL}$ poured at the site after incision of deep fascia but just before

() The Author(s). 2020 Open Access This article is distributed under the terms of the Creative Commons Attribution 4.0 International License (https://creativecommons. org/licenses/by-nc/4.0/), which permits unrestricted use, distribution, and non-commercial reproduction in any medium, provided you give appropriate credit to the original author(s) and the source, provide a link to the Creative Commons license, and indicate if changes were made. The Creative Commons Public Domain Dedication waiver (http://creativecommons.org/publicdomain/zero/1.0/) applies to the data made available in this article, unless otherwise stated. 
dividing the muscles and was left for 5 minutes, and $1.5 \mathrm{~g}$ made similarly poured into the surgical site after implant placement and wound wash and kept for 5 minutes after each pour and before proceeding further. The control group (30 patients) received an equal amount of saline used in the same way. The operating surgeon was unaware whether placebo or TXA had been used, the solution having been prepared under the supervision of the anesthesiologist in a random manner.

The blood volume was taken to be as $7 \%$ of the body weight as reported by Guyton and Hall. ${ }^{7}$ The assessment of blood loss was based purely on the fall of hemoglobin $(\mathrm{Hb})$ and hematocrit levels on the first and fifth postoperative days when compared to their levels immediately before surgery.

The blood volume on the fifth postoperative day is expected to have recovered to the preoperative levels, so the difference in the preoperative and the fifth postoperative $\mathrm{Hb}$ values was used to calculate $\mathrm{Hb}$ loss using the $\mathrm{Hb}$ balance formula of Gross. A unit of banked blood was considered to contain $52 \mathrm{~g} \mathrm{Hb} .{ }^{8,9}$ All patients were mobilized with aid on first postoperative day after obtaining satisfactory X-rays. Appropriate chemoprophylaxis for venous thromboembolism was given in all cases.

Comparison of quantitative variables was done using Student $t$ test and paired $t$ test. For comparing categorical data, Chi-square $\left(\chi^{2}\right)$ test was performed.

\section{Results}

Out of the 59 patients analyzed, 36 were females and 23 were males. In our study, there was a slight preponderance of female (61\%) patients when compared to male patients (39\%), with 29 left and 30 right hips.

Most (60.8\%) of the fractures occurred due to fall at home. Age range of cases was 60 - to 96 -year-olds, and $17.4 \%$ of the patients were more than 80 years old.

The mean preoperative estimated blood volume of patients in the study group was $4,622.41 \mathrm{~mL}$, while in the control group it was $4,769.33 \mathrm{~mL}$.

The $\mathrm{Hb}$ level fell to $9.90( \pm 1.48) \mathrm{g} / \mathrm{dL}$ on the first postoperative day in the study group, while it fell to $9.80( \pm 1.26) \mathrm{g} / \mathrm{dL}$ in the control group when compared to the preoperative $\mathrm{Hb}$ levels of $11.07( \pm 1.69) \mathrm{g} / \mathrm{dL}$ and $11.49( \pm 1.59) \mathrm{g} / \mathrm{dL}$ in study and control group, respectively. On the fifth postoperative day, $\mathrm{Hb}$ levels were $9.92( \pm 1.25) \mathrm{g} / \mathrm{dL}$ in the study group, while in the control group they were $9.51( \pm 1.09) \mathrm{g} / \mathrm{dL}$. The decline in the Hb levels in the control group on fifth postoperative day was $1.97 \pm 0.67 \mathrm{~g} / \mathrm{dL}$, whereas the decline in the $\mathrm{Hb}$ levels of the study group was 1.15 $\pm 0.40 \mathrm{~g} / \mathrm{dL}$. The patients who received TXA had a significantly less decline ( $p$ value 0.001 ) in the $\mathrm{Hb}$ levels when compared to those who received placebo.

The total Hb Loss on fifth postoperative day was $77.75 \mathrm{~g}$ in the study group which was less than that in the control group where it was $117.88 \mathrm{~g}$.

In the study group, the hematocrit fell to $29.90( \pm 4.07) \%$ on the first postoperative day and $30.01( \pm 3.66) \%$ on the fifth postoperative day from $32.76( \pm 7.39) \%$ preoperatively. In the control group, it fell to $30.05( \pm 4.05) \%$ on the first postoperative day and $30.01( \pm 3.66) \%$ on the fifth postoperative day from $34.75( \pm 4.75) \%$ preoperatively. Thus, the fall in the Hct labels in the study group were significantly less than that in the control group.

We observed in the study group that the mean blood loss to $694.14 \mathrm{~mL}$ which was less than the mean blood loss of $1,000.27 \mathrm{~mL}$ in the control group. The association of decreased blood loss in the study group (topical tranexamic acid use) when compared to the blood loss in the control group was statistically significant ( $p$ value $=0.001$ ).

Blood transfusion was given to 17 patients, of which 9 were in the study group and 8 in control group. However, there were some factors that confounded these data (explained below).

Complications observed were a superficial seroma of the wound in four patients (two in each) and low-grade fever in three patients ( 2 in study and 1 in control group). One patient (control group) had prolonged fever, superficial wound infection and soakage, and had to be taken for wound lavage after 1 month, and the patient recovered subsequently. There was no difference in the complication rate in both the groups, and there was no incidence of any thromboembolic phenomenon or any other systemic side effects related to TXA in either group.

\section{Discussion}

Pharmacological agents to reduce the operative blood loss have been a matter of intense study. ${ }^{10,11}$ Out of these, TXA has proved its worth over a period of many years. ${ }^{12}$ Initially, it had been used only intravenously in a large number of surgeries such as, cardiac, gynecological, dental, and urogenital procedures.

The use of TXA in orthopedic surgeries has gained prominence over the last few years, and it has now become an essential tool for reducing the blood loss and also the morbidity and mortality associated with blood transfusions. Concerns about systemic side effects such as venous thromboembolism have led to an interest in topical use and determining the optimum dose. A lot of work has been done on the use of TXA in TKA and THA, and indeed surgeons have started using intravenous TXA routinely for these surgeries. However, there is no current recommendation for its routine use in HA patients considering that they are expected to have less blood loss than THA. Patients undergoing HA are elderly and frail and are already at risk of thromboembolism and complications associated with blood transfusions. So, we evaluated topical use of TXA instead of $\mathrm{I} / \mathrm{V}$ in these patients to address both these issues.

Various authors have compared the preoperative $\mathrm{Hb}$ levels with postoperative $\mathrm{Hb}$ levels in their studies on different postoperative days to calculate blood loss (as shown in Table 1). In our study, we have used fifth postoperative day $\mathrm{Hb}$ levels for comparison with the preoperative ones, considering the $\mathrm{Hb}$ level on postoperative day 5 to be a better indicator of actual $\mathrm{Hb}$ values; hemodilution due to intravenous fluids is expected to normalize by then, and blood volume is restored back to normal values.

The mean pre-op Hb levels in the study group $(11.07 \pm 1.69 \mathrm{~g} / \mathrm{dL})$ and in the control group $(11.49 \pm 1.59 \mathrm{~g} / \mathrm{dL})$ was different, and this was not significant. Even the fifth postoperative day $\mathrm{Hb}$ levels in the study group were $9.92 \pm 1.25 \mathrm{~g} / \mathrm{dL}$ and in the control group were $9.51 \pm 1.09 \mathrm{~g} / \mathrm{dL}$ and were similar statistically. However, the decline in $\mathrm{Hb}$ levels in the control group was $1.97 \pm 0.60 \mathrm{~g} / \mathrm{dL}$, whereas the decline in the $\mathrm{Hb}$ levels of study group was $1.15 \pm 0.40 \mathrm{~g} / \mathrm{dL}$ which was significant ( $p$ value 0.001 ).

We found a lower mean blood loss of $694.14 \mathrm{~mL} \pm 270.54 \mathrm{~mL}$ in the patients in who TXA was used (study group) when compared to $1,000.27 \pm 409.17 \mathrm{~mL}$ of blood loss in the patients, where TXA was not used (control group). The difference was statistically significant ( $p$ value 0.001 ). This result has been compared to other studies in Table 2. It seems prudent to conclude that topical use of TXA is efficacious for decreasing blood loss in patients undergoing HA. 
Table 1: Comparison of Hb levels in patients who received TXA with controls

\begin{tabular}{|c|c|c|c|c|c|c|}
\hline Authors & Groups & Pre-op Hb (g/dL) & 1st post-op day $\mathrm{Hb}$ & 2nd post-op day $\mathrm{Hb}$ & 3rd post-op day $\mathrm{Hb}$ & 5th post-op day $\mathrm{Hb}$ \\
\hline \multirow[t]{2}{*}{ Yue et al. ${ }^{13}$} & Study & $13.42 \pm 0.92$ & & & $10.59 \pm 0.88$ & \\
\hline & Control & $13.54 \pm 1.11$ & & & $9.38 \pm 0.63$ & \\
\hline \multirow[t]{2}{*}{ Martin et al. ${ }^{14}$} & Study & $13.60 \pm 1.70$ & & & & \\
\hline & Control & $13.63 \pm 1.63$ & & & & \\
\hline \multirow[t]{2}{*}{ Emara et al. ${ }^{15}$} & Study & $12.80 \pm 1.00$ & $10.7 \pm 1.60$ & & & \\
\hline & Control & $13.20 \pm 1.20$ & $9.00 \pm 1.10$ & & & \\
\hline \multirow[t]{2}{*}{ Kang et al. ${ }^{16}$} & Study & $13.03 \pm 0.28$ & & $9.93 \pm 0.19$ & & \\
\hline & Control & $10.97 \pm 0.20$ & & $9.58 \pm 0.11$ & & \\
\hline \multirow[t]{2}{*}{ Liu et al. ${ }^{17}$} & Study & $11.95 \pm 1.27$ & $10.32 \pm 1.77$ & & $9.32 \pm 1.17$ & \\
\hline & Control & $12.22 \pm 0.97$ & $10.32 \pm 0.97$ & & $9.71 \pm 1.05$ & \\
\hline Our Study & Study & $11.07 \pm 1.69$ & $9.90 \pm 1.48$ & & & $9.92 \pm 1.25$ \\
\hline$n=29 n=30$ & Control & $11.49 \pm 1.59$ & $9.80 \pm 1.26$ & & & $9.51 \pm 1.09$ \\
\hline
\end{tabular}

Some of the authors have used $\mathrm{Hb}$ values in $\mathrm{g} / \mathrm{L}$ rather than $\mathrm{g} / \mathrm{dL}$. To enable proper comparison the Hb values have been changed to $\mathrm{g} / \mathrm{dL}$ wherever necessary in this table

Table 2: Comparison of mean blood in patients who received TXA with controls \& the TXA regimens

\begin{tabular}{|c|c|c|c|c|c|c|}
\hline \multirow[b]{2}{*}{ Authors } & \multirow[b]{2}{*}{ Operations } & \multirow{2}{*}{$\begin{array}{l}\text { No. of cases study/ } \\
\text { control group }\end{array}$} & \multirow[b]{2}{*}{ TXA regime } & \multicolumn{2}{|c|}{ Mean blood loss in $\mathrm{mL}$} & \multirow[b]{2}{*}{$p$ value } \\
\hline & & & & Study group & Control group & \\
\hline Yue et al. ${ }^{13}$ & THA & $n=52 / n=49$ & $3 \mathrm{~g}$ in $150 \mathrm{~mL} \mathrm{NS}$ & $945.5 \pm 331.7$ & $1255.5 \pm 193.5$ & $<0.001$ \\
\hline Gilbody et al. ${ }^{18}$ & THA & $n=86 / n=88$ & $3 \mathrm{~g}$ in $100 \mathrm{~mL}$ NS & $1312 \pm 367$ & $1556 \pm 370$ & $<0.0001$ \\
\hline Xu et al. ${ }^{19}$ & THA & $n=113 / n=111$ & $3 \mathrm{~g}$ in $40 \mathrm{~mL}$ NS & $730 \pm 296$ & $1048 \pm 295$ & 0.001 \\
\hline Emara et al. ${ }^{15}$ & $\mathrm{HA}$ & $n=20 / n=20$ & $1.5 \mathrm{~g}$ in $100 \mathrm{~mL}$ NS & $625 \pm 35$ & $1100 \pm 30$ & $<0.05$ \\
\hline Kang et al. ${ }^{16}$ & $\mathrm{HA}$ & $n=40 / n=40$ & $3 \mathrm{~g}$ in $100 \mathrm{~mL}$ NS & $600 \pm 53$ & $737 \pm 62$ & 0.099 (NS) \\
\hline Our study & $\mathrm{HA}$ & $n=29 / n=30$ & $3 \mathrm{~g}$ in $100 \mathrm{~mL}$ NS & $694.14 \pm 270.54$ & $1000.27 \pm 409.17$ & 0.001 \\
\hline
\end{tabular}

The regime of topical TXA was different in different previous studies. From application via gauze, ${ }^{13}$ injection of TXA solution in the joint ${ }^{14}$ to application in femoral canal and acetabulum, ${ }^{20}$ the methods of application are varied. Yet, all seem to be effective in reducing blood loss. We used a simple method of soft tissue application and obtained similar results as others in their studies showing that method and regimen may not matter much when it comes to efficacy.

In our study, blood transfusion was given to 17 patients of which $9(31 \%)$ were in the study group and $8(26.7 \%)$ in control group. In many patients, these blood transfusions became necessary, as the preoperative $\mathrm{Hb}$ was less than the universally recommended preoperative $\mathrm{Hb}$ of $10.0 \mathrm{~g} / \mathrm{dL}$. Almost double patients in the study group had low preoperative $\mathrm{Hb}$ values when compared to control group, despite which the patients needing transfusion were almost equal in the two groups. Seven of the nine patients in the study group who received blood transfusion had preoperative $\mathrm{Hb}$ lower than $10.0 \mathrm{~g} / \mathrm{dL}$, while only three of eight patients in the control group who received blood transfusion had a preoperative $\mathrm{Hb}$ lower than $10.0 \mathrm{~g} / \mathrm{dL}$. Hence, TXA reduced the need of transfusion if preoperative $\mathrm{Hb}$ values are taken into account.

There is no consensus among studies in transfusion rates (Table 3). Each study uses different criteria and threshold for blood transfusion. Thus, there is clear bias, and these rates are not comparable between studies. Perhaps, we need to evaluate need of transfusion in peri-operative patients in a prospective manner so that we can have clear guidelines for the same. This would not only avoid the risk of unnecessary blood transfusions but also remove biases in decision-making.
Table 3: Comparison of transfusions rate in patients who received TXA with controls

\begin{tabular}{|c|c|c|}
\hline \multirow[b]{2}{*}{ Authors } & \multicolumn{2}{|c|}{ Transfusion rates } \\
\hline & Study (\%) & Control (\%) \\
\hline Martin et al. ${ }^{14}$ & 14.3 & 20 \\
\hline Emara et al. ${ }^{15}$ & 5 & 35 \\
\hline Wei et al. ${ }^{20}$ & 6 & 26 \\
\hline Xu et al. ${ }^{19}$ & 5.3 & 19.8 \\
\hline Lee et al. ${ }^{21}$ & 5 & 35 \\
\hline Kang et al. ${ }^{16}$ & 45 & 60 \\
\hline Our study & 31 & 26.7 \\
\hline
\end{tabular}

The complications observed as discussed earlier were similar in the two groups. Yue et al. in their study found postoperative superficial infections in one case and wound secretions in five patients where topical TXA was used and in seven patients where TXA was not used. ${ }^{13}$ Wei et al. could not find any significant difference in wound complications with topical TXA as previously feared that the increase in surgical time would lead to more complications. ${ }^{20}$

In our study, we did not find any clinical evidence of thromboembolism, and hence tests like D-dimer and Doppler sonography for DVT did not become necessary. Workers like Emara et al., ${ }^{15}$ Liu et al., ${ }^{17}$ Kang et al., ${ }^{16}$ and Konig et al. ${ }^{22}$ also found no thromboembolic complications in their study. However, Xu et al. ${ }^{19}$ have reported cases of DVT in their study (one each in the study and control group). Alshryda et al. ${ }^{23}$ have reported two cases in each 
group in their study of 161 patients. Similarly, Gilbody et al. ${ }^{18}$ have reported one case of pulmonary embolism in the TXA group and one case of DVT in the patients who did not receive TXA. Thus. we conclude that topically applied TXA seems safe and at the same time retains the efficacy in lowering blood loss.

\section{Conclusion}

The use of topical TXA in HA of hip joint is both safe and efficacious in reducing perioperative blood loss and need of blood transfusion. We recommend that surgeons routinely use topical TXA for the same regardless of the regimen and method of application.

\section{ACKnowledgments}

We thank Prof Mandeep Dhillon for his immense help in writing the manuscript, without which this paper would not have seen light of the day.

\section{References}

1. Cooper C, Campion G, Melton LJ3rd. Hip fractures in the elderly: A world-wide projection. Osteoprosis Int 1992;2(6):285-289. DOI: 10.1007/BF01623184.

2. National hip fracture database (NHFD) annual report 2017. Falls and fragility fracture audit programme. Royal College of Physicians. https://www.nhfd.co.uk/files/2017Reportfiles/NHFD-Annual Report2017.pdf (date last accessed 16 August 2018).

3. Wong J, Abrishami A, El Beheiry H, et al. Topical application of tranexamic acid reduces postoperative blood loss in total knee Arthroplasty: a randomized, controlled trial. J Bone Joint Surg Am 2010;92(15):2503-2513. DOI: 10.2106/JBJS.I.01518.

4. Panteli M, Papakostidis C, Dahabreh Z, et al. Topical tranexamic acid in total knee replacement: a systematic review and meta-analysis. Knee 2013;20(5):300-309. DOI: 10.1016/j.knee.2013.05.014.

5. Alshryda S, Sarda P, Sukeik M, et al. Tranexamic acid in total knee replacement: a systematic review and meta-analysis. J Bone Joint Surg Br 2011;93(12):1577-1585. DOI: 10.1302/0301-620X.93B12.26989.

6. Hiippala ST, Strid LJ, Wennerstrand MI, et al. Tranexamic acid radically decreases blood loss and transfusions associated with total knee arthroplasty. Anesth Analg 1997;84(4):839-844. DOI: 10.1213/00000539-199704000-00026.

7. Guyton CA, Hall EJ. The body fluid compartments: Extracellular and intracellular fluids; Interstitial fluid and oedema. The text book of medical physiology. 10th ed., New Delhi: WB Saunders company; Pennsylvania and Harcourt india private limited; 2000. pp. 264-278.

8. Good L, Peterson E, Lisander B. Tranexamic acid decreases external blood loss but not hidden blood loss in total knee replacement. $\mathrm{Br} \mathrm{J}$ Anaesth 2003;90(5):596-599. DOI: 10.1093/bja/aeg111.
9. Gross JB. Estimating allowable blood loss corrected for dilution. Anesthesiology 1983;58(3):277-280. DOI: 10.1097/00000542198303000-00016.

10. Panteli M, Pountos I, Giannoudis PV. Pharmacological adjuncts to stop bleeding: Options and effectiveness. Eur J Trauma Emerg Surg 2016;42(3):303-310. DOI: 10.1007/s00068-015-0613-x.

11. Verstraete M. Clinical application of inhibitors of fibrinolysis. Drugs 1985;29(3):236-261. DOI: 10.2165/00003495-198529030-00003.

12. Dunn CJ, Goa KL. Tranexamic acid - a review of its use in surgery and other indications. Drugs 1999;57(6):1005-1032. DOI: 10.2165/00003495-199957060-00017.

13. Yue $C$, Kang $P$, Yang $P$, et al. Topical tranexamic application of tranexamic acid in primary total hip Arthroplasty: A randomised double-blind controlled trial. J Arthroplasty 2014;29(12):2452-2456. DOI: 10.1016/j.arth.2014.03.032

14. Martin JG, Cassatt KB, Kincaid-Cinnamon KA, et al. Topical administration of tranexamic acid in primary total hip and total knee Arthroplasty. J Arthroplasty 2014;29(5):889-894. DOI: 10.1016/j. arth.2013.10.005.

15. Emara WM, Moez KK, Elkhouly AH. Topical versus intravenous tranexamic acid as a blood conservation intervention for reduction of Post-operative bleeding in hemiarthroplasty. Anesth Essays Res 2014;8(1):48-53. DOI: 10.4103/0259-1162.128908.

16. Kang JS, Moon KH, Kim BS, et al. Topical administration of TXA in hip Arthroplasty. Int Orthop 2017;41(2):259-263. DOI: 10.1007/s00264016-3195-2.

17. Liu W, Hui $\mathrm{H}$, Zhang $\mathrm{Y}$, et al. Intra-articular tranexamic acid injection during the hip Hemi-Arthroplasty in elderly patients: A retrospective study. Geriatr Orthop Surg Rehabil 2018;9:215145931880385. DOI: 10.1177/2151459318803851.

18. Gilbody J, Dhotar HS, Perruccio AV, et al. Topical tranexamic acid reduces transfusion rates in total hip and knee Arthroplasty. J Arthroplasty 2014;29(4):681-684. DOI: 10.1016/j.arth.2013.09.005.

19. Xu X, Li X, Liu W, et al. Longtime soaking of high concentration tranexamic acid in total hip arthropasty: a prospective randomized controlled trial in 224 patients. Pak J Med Sci 2015;31(6):1306-1311. DOI: 10.12669/pjms.316.8465.

20. Wei W, Wei B. Comparison of topical and intravenous tranexamic acid on blood loss and transfusion rates in total hip arthroplasty. J Arthroplasty 2014;29(11):2113-2116. DOI: 10.1016/j.arth.2014.07.019.

21. Lee C, Freeman R, Edmondson M, et al. The efficacy of tranexamic acid in hip hemiarthroplasty: an observational cohort study. Injury 2015;46(10):1978-1982. DOI: 10.1016/j.injury.2015.06.039.

22. Konig G, Hamlin BR, Waters JH. Topical tranexamic acid reduces blood loss and transfusion rates in total hip and total knee arthroplasty. $J$ Arthroplasty 2013;28(9):1473-1476. DOI: 10.1016/j.arth.2013.06.011.

23. Alshryda S, Mason J, Sarda P, et al. Topical (intra-articular) tranexamic acid reduces blood loss and transfusion rates following total hip replacement: a randomised controlled trial (TRANX-H). J Bone Joint Surg Am 2013;95(21):1969-1974. DOI: 10.2106/JBJS.L.00908. 